\title{
Neural processing of respiratory sensations when breathing becomes more difficult and unpleasant
}

\author{
Andreas von Leupoldt ${ }^{1,2,3,4}$ *, Margaret M. Bradley ${ }^{4}$, Peter J. Lang ${ }^{4}$ and Paul W. Davenport ${ }^{1}$ \\ Department of Physiological Sciences, University of Florida, Gainesville, FL, USA \\ 2 Department of Psychology, University of Hamburg, Hamburg, Germany \\ ${ }^{3}$ Department of Systems Neuroscience, University Medical Center Hamburg-Eppendorf, Hamburg, Germany \\ ${ }^{4}$ NIMH Center for the Study of Emotion and Attention, University of Florida, Gainesville, FL, USA
}

Edited by:

Karen Wheeler-Hegland, University of Florida, USA

\section{Reviewed by:}

Pei-Ying S. Chan, Chang Gung

University, Taiwan

E. Fiona Bailey, University of Arizona, USA

\section{${ }^{*}$ Correspondence:}

Andreas von Leupoldt, Department of Psychology, University of Hamburg,

Von-Melle-Park 5, 20146 Hamburg,

Germany.

e-mail: andreas.vonleupoldt@

uni-hamburg.de

\begin{abstract}
The accurate perception of respiratory sensations is important for the successful management and treatment of respiratory diseases. Previous studies demonstrated that external stimuli such as affective pictures and distracting films can impact the perception and neural processing of respiratory sensations. This study examined the neural processing of respiratory sensations when breathing as an internal stimulus is manipulated and becomes more difficult and unpleasant. Sustained breathing through an inspiratory resistive load was used to increase perceived breathing difficulty in 12 female individuals without respiratory disease. Using high-density EEG, respiratory-related evoked potentials (RREP) to short inspiratory occlusions were recorded at early versus late time points of sustained loaded breathing. Ratings of perceived intensity and unpleasantness of breathing difficulty showed an increase from early to late time points of loaded breathing ( $p<0.01$ and $p<0.05$, respectively). This was paralleled by significant increases in the magnitudes of RREP components N1, P2, and P3 ( $p<0.01, p<0.05$, and $p<0.05$, respectively). The present results demonstrate increases in the neural processing of respiratory sensations when breathing becomes more difficult and unpleasant. This might reflect a protective neural mechanism allowing effective response behavior when air supply is at risk.
\end{abstract}

Keywords: brain, breathing difficulty, breathlessness, dyspnea, EEG, neural processing, perception, respiratory-related evoked potential

\section{INTRODUCTION}

The accurate perception of respiratory sensations such as dyspnea is of considerable importance for successful self-management and treatment of various respiratory diseases including asthma or chronic obstructive pulmonary disease (COPD). Respiratory sensations provide the basis for the patients' motivation to timely initiate adequate health behavior such as medication use or physician visits (Banzett et al., 2000; Lansing et al., 2009). Reduced as well as over-perception of respiratory sensations has been shown to be associated with negative treatment outcome in patients with asthma or COPD (Barnes, 1994; Kikuchi et al., 1994; Kifle et al., 1997; Magadle et al., 2002; Main et al., 2003; Feldman et al., 2007; GOLD, 2008).

Psychological factors such as affective state or attentional focus have been demonstrated to considerably impact the perception of respiratory symptoms (Rietveld, 1998; Chetta et al., 2005; von Leupoldt and Dahme, 2007; Janssens et al., 2009). Moreover, previous studies showed that the parallel processing of affective pictures or attention distracting films or texts also impacts the neural processing of respiratory sensations (Harver et al., 1995; Webster and Colrain, 2000; Davenport et al., 2007; von Leupoldt et al., 2008, 2010c). Common to these previous studies is their exclusive focus on the impact of external stimuli on the neural processing of internal respiratory sensations, which compete for neural processing resources of the respiratory sensations. However, recent findings demonstrated that also internal stimuli, i.e., internal stimulation of the respiratory system itself, can influence respiratory perception. Alexander-Miller and Davenport (2010) reported that sustained breathing through resistive loads $\left(>15 \mathrm{cmH}_{2} 0 / \mathrm{L} / \mathrm{s}\right)$ for 10 inspirations prompted increased reports of breathing difficulty in female individuals when compared to respiratory stimulation by a single loaded inspiration. However, the underlying neural processes have not been addressed in that study.

Therefore, the present study examined the neural processing of respiratory sensations when loaded breathing serves as an internal stimulus and becomes more difficult and unpleasant. As in the study by Alexander-Miller and Davenport (2010), sustained breathing through an inspiratory resistive load was used to increase the level of perceived breathing difficulty. The respiratory-related evoked potential (RREP) extracted from the electroencephalogram (EEG) was used as a measure of cerebral cortical activity, which was elicited by short inspiratory occlusions at early versus late time points of loaded breathing (Davenport et al., 1986; Logie et al., 1998; Redolfi et al., 2005; Huang et al., 2008; Chan and Davenport, 2010). The early RREP components Nf, P1 and N1 ( $<130 \mathrm{~ms}$ post stimulus) presumably reflect the initial arrival and first-order sensory processing of afferent respiratory signals in sensorimotor regions with $\mathrm{N} 1$ influenced by endogenous factors unrelated to the stimulus, e.g., attentional processes. The later components P2 and P3 (>150 ms post stimulus) are related to subsequent higher-order cognitive processing in other cortical areas (Chan and Davenport, 2010; von Leupoldt et al., 2010b). 
Theories of motivated attention (Lang et al., 1997; Bradley and Lang, 2007) postulate that affectively arousing and motivationally relevant stimuli naturally demand neural resources, and we therefore hypothesized that the neural processing of inspiratory occlusions would be heightened when breathing is more difficult and unpleasant. Specifically, greater magnitudes were expected for RREP components N1, P2, and P3 during late compared to early time points of sustained resistive load breathing, which would converge with previous studies demonstrating a specific impact of emotion processing or attentional distraction on these components (Harver et al., 1995; Webster and Colrain, 2000; Davenport et al., 2007; von Leupoldt et al., 2010c).

\section{MATERIALS AND METHODS PARTICIPANTS}

After providing informed written consent, 12 healthy, non-smoking female volunteers without history of respiratory disease (Table 1) participated in this study, approved by the Institutional Review Board of the University of Florida. Male volunteers were not included because the effects of sustained loaded breathing on respiratory perception were mainly observed in female participants in the study by Alexander-Miller and Davenport (2010). Prior to testing, participants were informed that the aim of the study was the assessment of physiological responses (brain activity, breathing responses) and subjective perception during different levels of breathing difficulty. Baseline lung function was measured by spirometry (SpiroPro, Cardinal Health, Hoechberg, Germany) according to international guidelines (Miller et al., 2005). All subjects had normal spirometric pulmonary function (Table 1).

\section{RESISTIVE LOAD BREATHING}

As in the study by Alexander-Miller and Davenport (2010), a sensation of breathing difficulty was induced by inspiration through a resistive load which superimposes increased work to the respiratory muscles (Harver and Mahler, 1998). However, besides the additional measurement of the RREP, the present study used only one instead of six resistive loads of varying difficulty level. Participants wore a nose clip and breathed via a mouthpiece through a breathing circuit with a non-rebreathing valve (Hans Rudolph Inc., Kansas City, USA). The inspiratory port of the valve was connected in series to a pneumotachograph, a loading manifold and a pressure-activated occluder. The loading manifold consisted of an inspiratory resistive $\operatorname{load}\left(20 \mathrm{cmH}_{2} \mathrm{O} / \mathrm{L} / \mathrm{s}\right)$ that was introduced/removed from the inspiratory airflow by manual closing/opening of a side port. In order to prevent reflexive changes in the breathing pattern, which could

Table 1 | Mean (SD) baseline characteristics of participants.

\begin{tabular}{lc}
\hline Characteristics & Data \\
\hline Age (years) & $23.3(5.0)$ \\
Weight (kg) & $62.4(12.3)$ \\
Height (cm) & $166.1(7.7)$ \\
Forced expiratory volume in 1 s (L) & $3.52(.58)$ \\
Forced expiratory volume in 1 s (\% of predicted value) & $110.0(14.0)$ \\
Forced vital capacity (L) & $4.11(.74)$ \\
Forced vital capacity (\% of predicted value) & $111.2(16.3)$
\end{tabular}

reduce the effects of resistive load breathing, participants maintained peak inspiratory airflow during the entire experiment by airflow targeting (Zhao et al., 2003). They were instructed to have the peak of their inspiratory airflow (measured with the pneumotachograph) with each breath "hit" the target line on an oscilloscope.

\section{MEASUREMENT OF PERCEIVED BREATHING DIFFICULTY}

Following a visual prompt, participants rated the perceived intensity and unpleasantness of their breathing difficulty on separate visual analog scales (VAS, Noseda et al., 1992). VAS were presented as paper-and-pencil versions and ranged from 0 to $10 \mathrm{~cm}(0=$ not noticeable/unpleasant and $10=$ maximally imaginable intensity/ unpleasantness). VAS for intensity and unpleasantness were presented in randomized order.

\section{RREP MEASUREMENT AND DATA REDUCTION}

Details on RREP measurement and data reduction with a comparable technical set up have been previously described (von Leupoldt et al., 2010c). Briefly, inspiration was interrupted at the third and at the 12 th loaded breath for $160 \mathrm{~ms}$ by manual occluder activation. Occlusions were presented after the onset of inspiration as indicated by the mouth pressure signal with a parallel marker signal sent to the EEG computer.

Electroencephalogram data were recorded from the scalp using a 129-channel system (Electrical Geodesics Inc., Eugene, USA) with scalp impedance $<50 \mathrm{k} \Omega$, sampling rate $=250 \mathrm{~Hz}$, vertex sensor as reference electrode and on-line bandpass filter $(0.1-56 \mathrm{~Hz})$. All further processing was performed offline, using functions built into BESA 5.1. After low-pass filtering $(30 \mathrm{~Hz})$ and artifact corrections, occlusion epochs were extracted (200 ms pre- and $1300 \mathrm{~ms}$ poststimulus) and averaged separately for the third and 12th loaded breaths for each participant using a maximum of $200 \mu \mathrm{V}$ as cutoff amplitude. Based on previous reports (e.g., Davenport et al., 1986; Logie et al., 1998; Chan and Davenport, 2010; von Leupoldt et al., 2010c), the RREP components were identified as follows: $\mathrm{Nf}=$ negative peak in the frontal region (latency: $25-50 \mathrm{~ms}$ ), $\mathrm{P} 1=$ positive peak in the centro-parietal region (latency: $45-65 \mathrm{~ms}$ ), $\mathrm{N} 1=$ negative peak in the centro-lateral region (latency: $85-125 \mathrm{~ms}$ ), $\mathrm{P} 2=$ positive peak in the central region (latency: 160-230 ms), and P3 = positive peak in the centro-parietal region (latency: 250-350 ms).

\section{PROCEDURE}

After standardized instructions and positioning of the EEG sensor net and nose clip, participants were seated in a recliner and breathed through the respiratory circuit. The experimental protocol was divided into four blocks of approximately $11 \mathrm{~min}$ each, separated by 5 -min resting intervals. Each block began with a 1-min epoch of adaptation to the mouthpiece breathing without presentation of the resistive load and without inspiratory occlusions which was followed by five trials of sustained resistive load breathing. Each trial consisted of 12 consecutive loaded inspirations and was followed by a 1-min epoch of unloaded breathing. Inspiratory occlusions were presented at the onset of the third and 12th loaded breath during each trial, resulting in a total of 20 presented occlusions per person for both early and late time points of loaded breathing. For highdensity EEG systems, this number of occlusions converges with the minimum signal-to-noise criteria for obtaining acceptable RREP 
components N1, P2, and P3 which were the focus of the present study (von Leupoldt et al., 2010a). Each block contained an additional trial of sustained resistive load breathing, but without the presentation of inspiratory occlusions. During this trial, participants rated the perceived intensity and unpleasantness of their breathing difficulty on the VAS at an early (second loaded breath) and late time point (12th loaded breath) of loaded breathing. Ratings for the early time point were obtained at the second loaded breath because the early inspiratory occlusions were presented at the onset of the third breath, i.e., when the participants had already experienced two loaded breaths, but their third breath was yet not loaded at the time of occlusion presentation. Therefore, a rating at the second loaded breath seemed to more closely reflect the perceived early breathing difficulty at the time point of the early occlusion presentations, whereas a rating at the third loaded breath could have already overestimated the early breathing difficulty. The position of these rating trials between trials with the presentation of inspiratory occlusions was counterbalanced across the four blocks for each individual.

\section{ANALYSES}

Outcome measures are reported as means \pm standard deviations of the mean (SD) averaged across the early time points and across the late time points of loaded breathing and were compared with paired $t$-tests. All analyses were calculated with SPSS 15.0 software (SPSS Inc., Chicago, USA) using a significance level of $p<0.05$.

\section{RESULTS}

\section{PERCEIVED BREATHING DIFFICULTY}

Ratings of breathing difficulty confirmed that manipulation of breathing difficulty by using resistive loads was successful. As illustrated in Figure 1, a significant increase in ratings of perceived intensity and unpleasantness were found from the second to the 12th breath of loaded breathing, $p<0.01$ and $p<0.05$, respectively.

\section{RESPIRATORY-RELATED EVOKED POTENTIALS}

The number of artifact-free inspiratory occlusions averaged for the RREP were equivalent for probes presented at the third and 12th breath of loaded breathing (16.2 and 16.3, respectively).

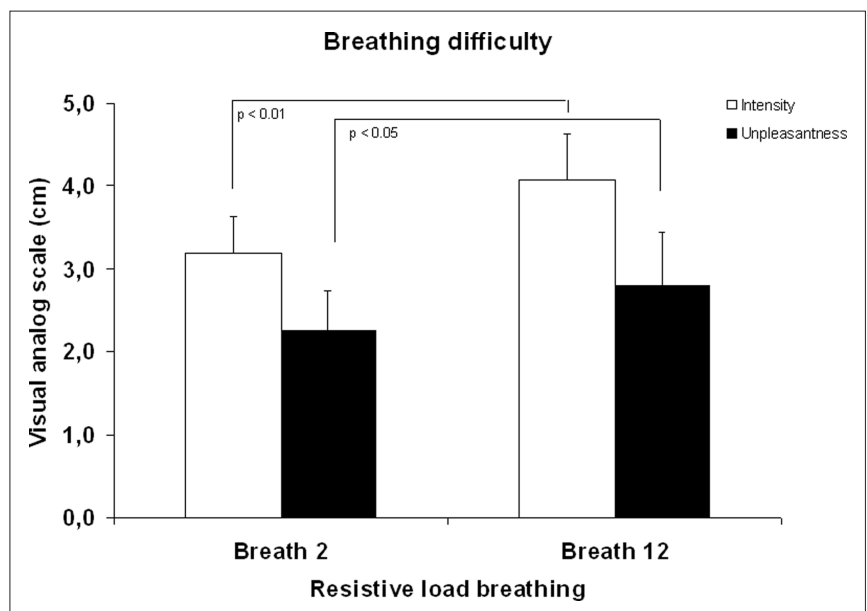

FIGURE 1 | Mean (SE) ratings of perceived intensity and unpleasantness of breathing difficulty.
As illustrated in Figure 2, the RREP components N1, P2, and P3 showed similar scalp localizations for occlusions presented at the third and 12th breath of loaded breathing. N1, P2, and P3 showed significant magnitude increases from the third to the 12 th breath of loaded breathing, $p<0.01, p<0.05$, and $p<0.05$, respectively (Figure 2; Table 2 ).

\section{DISCUSSION}

This study examined the modulation of neural processing of respiratory sensations when breathing itself is manipulated and serves as an internal aversive stimulus. The present results show that sustained breathing through an inspiratory resistive load increased the level of perceived intensity and unpleasantness of breathing difficulty which replicates recent observations by Alexander-Miller and Davenport (2010). Most importantly, increased breathing difficulty was accompanied by increased magnitudes of the RREP components $\mathrm{N} 1, \mathrm{P} 2$, and $\mathrm{P} 3$ which were elicited by parallel presentations of short inspiratory occlusions. These results suggest heightened neural processing of respiratory sensations when breathing becomes more difficult and unpleasant.

The present study, using breathing as internal stimulus, extends previous studies that found an impact of external stimuli on the neural processing of respiratory sensations (Harver et al., 1995; Webster and Colrain, 2000; Davenport et al., 2007; von Leupoldt et al., 2010c). For example, when inspiratory occlusions are imposed

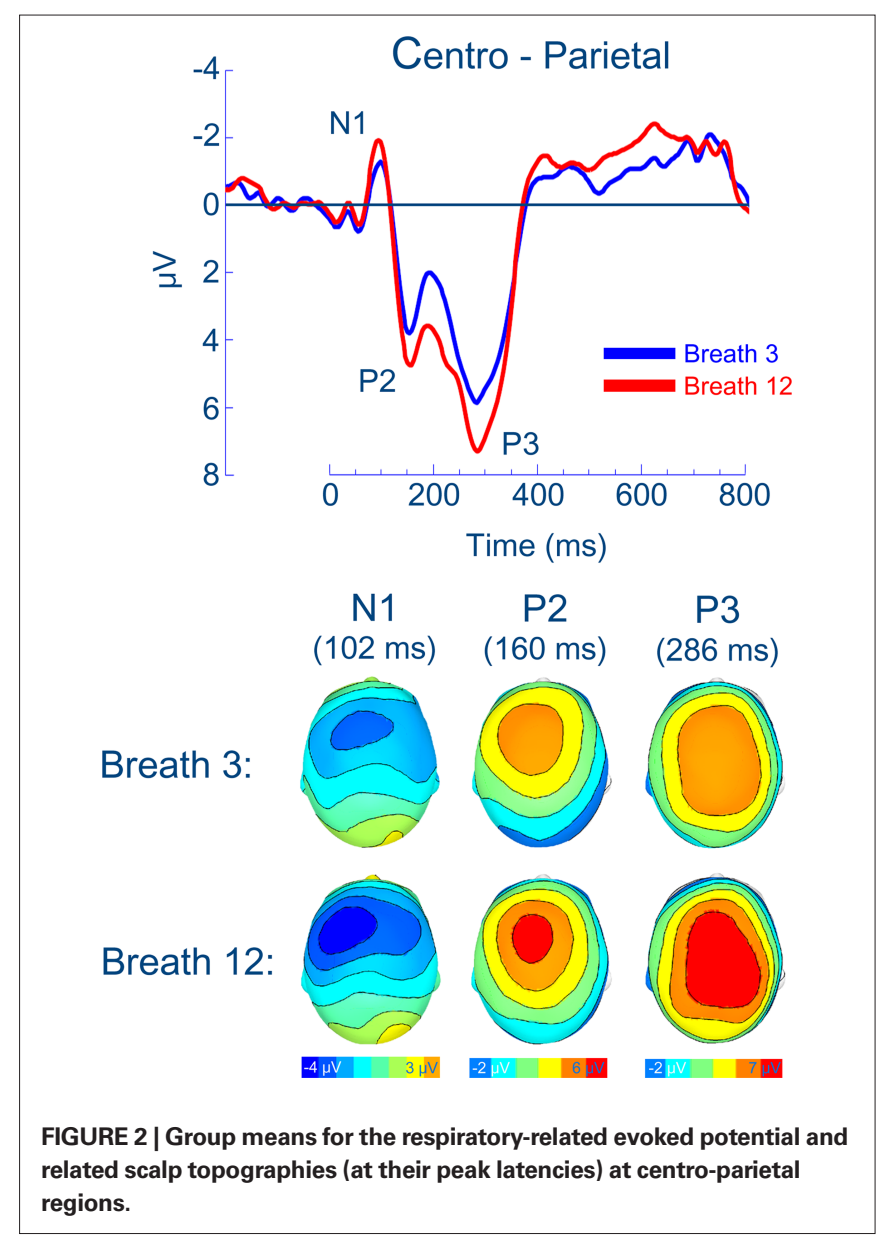


Table 2 | Mean (SD) amplitudes $(\mu \mathrm{V})$ of the respiratory-related evoked potential (RREP) for breath third and breath 12th during resistive load breathing.

\begin{tabular}{lrr}
\hline RREP & Breath 3 & Breath 12 \\
\hline N1 (centro-lateral) & $-1.61(2.96)$ & $-2.43(3.03)^{\dagger}$ \\
P2 (central) & $3.71(4.37)$ & $4.61(4.52)^{*}$ \\
P3 (centro-parietal) & $5.08(2.84)$ & $6.58(3.43)^{*}$ \\
\hline
\end{tabular}

${ }^{*} p<0.05,{ }^{\dagger} p<0.01$ (paired t-tests).

during conditions of attentional distraction by ongoing movie presentations or text reading, reduced magnitudes of $\mathrm{N} 1, \mathrm{P} 2$, and/or P3 are found, compared to conditions in which attention is directed to the respiratory stimulus (Harver et al., 1995; Webster and Colrain, 2000; Davenport et al., 2007). Similarly, short inspiratory occlusions presented when viewing unpleasant pictures elicited reduced magnitudes of $\mathrm{P} 2$ or $\mathrm{P} 3$ in low anxious individuals, but increased magnitudes in high anxious individuals (von Leupoldt, Chan et al., in submission; von Leupoldt et al., 2010c) when compared to neutral pictures. The latter findings were interpreted as reflecting motivated attention (Lang et al., 1997; Bradley and Lang, 2007), in which affectively arousing and motivationally relevant stimuli naturally demand neural processing capacities. Following this interpretation, the present results suggest that when breathing becomes more difficult and unpleasant and, thus, more motivationally relevant, sensations from the respiratory system demand greater attentional and neural resources. This might reflect a protective mechanism in which effective neural processing of aversive respiratory sensations prompts initiation of adequate behavioral responses (e.g., medication use, physician visits) in states of insufficient air supply with the ultimate goal of preventing physical harm.

We speculate that this mechanism plays a role in those patients with asthma or COPD who show problems in the perception of respiratory sensations and related negative treatment outcomes (Barnes, 1994; Kikuchi et al., 1994; Kifle et al., 1997; Magadle et al., 2002; Main et al., 2003; Feldman et al., 2007; GOLD, 2008). For instance, previous studies have hypothesized that some patients

\section{REFERENCES}

Alexander-Miller, S., and Davenport, P.W. (2010). Perception of multiple-breath inspiratory resistive loads in males and females. Biol. Psychol. 84, 147-149.

Banzett, R. B., Dempsey, J. A., O’Donnell, D. E., and Wamboldt, M. Z. (2000). Symptom perception and respiratory sensation in asthma. Am. J. Respir. Crit. Care Med. 162, 1178-1182.

Barnes, P. J. (1994). Blunted perception and death from asthma. N. Engl. J. Med. 330, 1383-1384.

Bradley, M. M., and Lang, P. J. (2007). “The International Affective Picture System (IAPS) in the study of emotion and attention," in Handbook of Emotion Elicitation and Assessment, eds J. A. Coan and J. J. B. Allen (New York: Oxford University Press), 29-46.
Chan, P. S., and Davenport, P. W. (2010). Respiratory related evoked potential measures of cerebral cortical respiratory information processing. Biol. Psychol. 84, 4-12.

Chetta, A., Foresi, A., Marangio, E., and Olivieri, D. (2005). Psychological implications of respiratory health and disease. Respiration 72, 210-215.

Davenport, P. W., Chan, P. Y., Zhang, W., and Chou, Y. L. (2007). Detection threshold for inspiratory resistive loads and respiratory-related evoked potentials. J. Appl. Physiol. 102, 276-285.

Davenport, P. W., Friedman, W. A., Thompson, F. J., and Franzen, O. (1986). Respiratory-related cortical potentials evoked by inspiratory occlusion in humans. J. Appl. Physiol. 60, 1843-1848.

might habituate to the repeated or chronic experience of breathing difficulty (Li et al., 2006; von Leupoldt et al., 2009; Wan et al., 2009). In this case, respiratory sensations might become less relevant and attention demanding, resulting in reduced neural processing of acute sensations risking under-perception and under-treatment. In contrast, other patients might show sensitization to repeated sensations of breathing difficulty and experience or interpret them in a catastrophizing manner as recently demonstrated in patients with asthma (De Peuter et al., 2008). For these patients, respiratory sensations presumably become highly relevant and attention demanding, resulting in increased neural processing of acute sensations, risking over-perception and over-treatment. Moreover, anxiety or negative affective states can further interact with these neural processes of respiratory perception (Janssens et al., 2009; von Leupoldt, Chan et al., in submission; von Leupoldt et al., 2010c). Because the generalizability of the present results in healthy, female individuals to patients with respiratory disorders is limited, future studies in respiratory patient groups are clearly warranted. In this regard, it will be interesting to examine whether the neural processing of respiratory sensations is associated with patients' anxiety levels, course of disease and treatment outcomes.

In summary, the present study found increased neural processing of respiratory sensations when breathing became more difficult and unpleasant. This might represent a protective neural mechanism that prompts effective response behavior in situations where air supply is at risk. Future studies will be important in determining whether respiratory patient groups show comparable patterns in their neural processing of respiratory stimuli and whether these patterns are related to individual anxiety levels, course of disease and treatment outcome.

\section{ACKNOWLEDGMENTS}

This study was supported by a stipend (Heisenberg-Stipendium, DFG LE 1843/9-1) from the German Research Society (Deutsche Forschungsgemeinschaft, DFG) to Andreas von Leupoldt and a grant from the National Institute of Mental Health (P50 MH 72850) to Peter J. Lang. The authors wish to thank Andreas Keil for his valuable support of the present study and all our participants.

De Peuter, S., Lemaigre, V., Van Diest, I., and Van den Bergh, O. (2008). Illness-specific catastrophic thinking and overperception in asthma. Health Psychol. 27, 93-99.

Feldman, J. M., McQuaid, E. L., Klein, R. B., Kopel, S. J., Nassau, J. H., Mitchell, D. K., Wamboldt, M. Z., and Fritz, G. K. (2007). Symptom perception and functional morbidity across a 1-year follow-up in pediatric asthma. Pediatr. Pulmonol. 42, 339-347.

Global Initiative for Chronic Obstructive Lung Disease (GOLD). (2008). Global Strategy for Diagnosis, Management, and Prevention of COPD. Available from: http://www.goldcopd.com.

Harver, A., and Mahler, D. A. (1998). "Perception of increased resistance to breathing," in Self-Management of
Asthma, eds H. Kotses and A. Harver (New York, NY: Decker), 35-61.

Harver, A., Squires, N., Bloch-Salisbury, E., and Katkin, E. (1995). Event-related potentials to airway occlusion in young and old subjects. Psychophysiology 32, 121-129.

Huang, J., Marcus, C. L., Bandla, P., Schwartz, M. S., Pepe, M. E., Samuel, J. M., Panitch, H. B., Bradford, R. M., Mosse, Y. P., Maris, J. M., and Colrain, I. M. (2008). Cortical processing of respiratory occlusion stimuli in children with central hypoventilation syndrome. Am. J. Respir. Crit. Care Med. 178, 757-764. Janssens, T., Verleden, G., De Peuter, S., Van Diest, I., and Van den Bergh, O. (2009). Inaccurate perception of asthma symptoms: a cognitive-affective framework and implications for 
asthma treatment. Clin. Psychol. Rev. 29, 317-327.

Kifle, Y., Seng, V., and Davenport, P. W. (1997). Magnitude estimation of inspiratory resistive loads in children with life-threatening asthma. Am. J. Respir. Crit. Care Med. 156, 1530-1535.

Kikuchi, Y., Okabe, S., Tamura, G., Hida, W., Homma, M., Shirato, K., and Takishima, T.(1994). Chemosensitivity and perception of dyspnea in patients with a history of near-fatal asthma. $N$. Engl. J. Med. 330, 1329-1334.

Lang, P. J., Bradley, M. M., and Cuthbert, B. N. (1997). "Motivated attention: affect, activation, and action," in Attention and Orienting: Sensory and Motivational Processes, eds P. J. Lang, R. F. Simons, and M. T. Balaban (Hillsdale, NJ: Lawrence Erlbaum Associates), 97-135.

Lansing, R. W., Gracely, R. H., and Banzett, R. B. (2009). The multiple dimensions of dyspnea: review and hypotheses. Respir. Physiol. Neurobiol. 167, 53-60.

Li, W., Daems, E., Van de Woestijne, K.P., Van Diest, I., Gallego, J., De Peuter, S., Bogaerts, K., and Van den Bergh, O. (2006). Air hunger and ventilation in response to hypercapnia: effects of repetition and anxiety. Physiol. Behav. $88,47-54$.

Logie, S. L., Colrain, I. M., and Webster, K.E. (1998). Source localisation of the early components of the respiratoryrelated evoked potential. Brain. Topogr. $11,153-164$.
Magadle, R., Berar-Yanay, N., and Weiner, P. (2002). The risk of hospitalization and near-fatal and fatal asthma in relation to the perception of dyspnea. Chest 121, 329-333.

Main, J., Moss-Morris, R., Booth, R., Kaptein, A. A., and Kolbe, J. (2003). The use of reliever medication in asthma: the role of negative mood and symptom reports. J. Asthma 40, 357-365.

Miller, M. R., Crapo, R., Hankinson, J., Brusasco, V., Burgos, F., Casaburi, R., Coates, A., Enright, P., van der Grinten, C. P., Gustafsson, P., Jensen, R., Johnson, D.C., MacIntyre, N., McKay, R., Navajas, D., Pedersen, O. F., Pellegrino, R., Viegi, G., Wanger, J., and ATS/ERS Task Force. (2005). Standardisation of spirometry. Eur. Respir. J. 26, 319-338.

Noseda, A., Schmerber, J., Prigogine, T., and Yernault, J. C. (1992). Perceived effect on shortness of breath of an acute inhalation of saline or terbutalline: variability and sensitivity of a visual analogue scale in patients with asthma or COPD. Eur. Respir. J. 5, 1042-1053.

Redolfi, S., Raux, M., Donzel-Raynaud, C., Morelot-Panzini, C., Zelter, M., Derenne, J. P., Similowski, T., and Straus, C. (2005). Effects of upper airway anaesthesia on respiratoryrelated evoked potentials in humans. Eur. Respir. J. 26, 1097-1103.

Rietveld, S. (1998). Symptom perception in asthma: a multidisciplinary review. J. Asthma 35, 137-146. von Leupoldt, A., and Dahme, B. (2007). Psychological aspects in the perception of dyspnea in obstructive pulmonary diseases. Respir. Med. 101, 411-422.

von Leupoldt, A., Keil, A., and Davenport, P. W. (2010a). Respiratory-related evoked potential measurements using high-density electroencephalography. Clin. Neurophysiol. doi:10.1016/j. clinph.2010.10.031

von Leupoldt, A., Keil, A., Chan, P. Y., Bradley, M. M., Lang, P. J., and Davenport, P. W. (2010b). Cortical sources of the respiratory-related evoked potential. Respir. Physiol. Neurobiol. 170, 198-201.

von Leupoldt, A., Vovk, A., Bradley, M. M., Keil, A., Lang, P. J., and Davenport, P. W. (2010c). The impact of emotion on respiratory-related evoked potentials. Psychophysiology 47, 579-586.

von Leupoldt, A., Sommer, T., Kegat, S. Baumann, H. J., Klose, H., Dahme, B., and Büchel,C. (2008). The unpleasantness of perceived dyspnea is processed in the anterior insula and amygdala. Am. J. Respir. Crit. Care Med. 177, 1026-1032.

von Leupoldt, A., Sommer, T., Kegat, S. Eippert, F., Baumann, H. J., Klose, H., Dahme, B., and Büchel, C. (2009). Down regulation of insular cortex responses to dyspnea and pain in asthma. Am. J. Respir. Crit. Care Med. 180, 232-238.

Wan, L., Van Diest, I., De Peuter, S., Bogaerts, K., and Van den Bergh, O. (2009). Repeated breathlessness experiences induced by hypercapnia: differential effects on intensity and unpleasantness. Chest 135, 455-461.

Webster, K. E., and Colrain, I. M. (2000). The respiratory-related evoked potential: effects of attention and occlusion duration. Psychophysiology 37, 310-318.

Zhao, W., Martin, A. D., and Davenport, P.W. (2003). Magnitude estimation of inspiratory resistive loads by doublelung transplant recipients. J. Appl. Physiol. 94, 576-582.

Conflict of Interest Statement: The authors declare that the research was conducted in the absence of any commercial or financial relationship that could be construed as a potential conflict of interest.

Received: 20 August 2010; accepted: 09 October 2010; published online: 04 November 2010.

Citation: von Leupoldt A, Bradley MM, Lang PJ and Davenport PW (2010). Neural processing of respiratory sensations when breathing becomes more difficult and unpleasant. Front. Physio. 1:144. doi: 10.3389/fphys.2010.00144

This article was submitted to Frontiers in Respiratory Physiology, a specialty of Frontiers in Physiology.

Copyright $\odot 2010$ von Leupoldt, Bradley, Lang and Davenport. This is an open-access article subject to an exclusive license agreement between the authors and the Frontiers Research Foundation, which permits unrestricted use, distribution, and reproduction in any medium, provided the original authors and source are credited. 